\title{
Primer Mundo y Tercer Mundo después de la Guerra Fría
}

\author{
Eric Hobsbawm \\ Profesor Emérito de \\ Historia Social y Económica, \\ Birbeck College, \\ Universidad de Londres
}

Esta exposición trata de los Estados Unidos y el Tercer Mundo después de la Guerra Fría. Sin embargo, este tema sólo se puede entender a partir de la larga historia de relaciones entre los países de Occidente, o el centro del sistema mundial, y la periferia. Esta historia empieza con el final del siglo XV, cuando los europeos, después de un milenio de estar a la defensiva contra invasores de Asia y Africa, empezaron su propia era de conquista mundial.

En esencia, esa conquista, por lo menos por algunos siglos, no estuvo basada en una mayor riqueza o una abrumadora superioridad técnica, aunque los avances científicos y técnicos en las regiones relevantes de Europa occidental eran ya más dinámicos y en algunos aspectos más avanzados que en cualquier otro lugar. Ciertamente, recién en el siglo XIX apareció la enorme brecha entre el producto nacional bruto per cápita de Occidente y al menos de algunos de los países no occidentales.

$\square$ Este texto es una versión editada de la disertación del profesor Eric Hobsbawm en el seminario "El Mundo frente al Milenio", realizado el día 25 de noviembre de 1998, organizado conjuntamente por CENDA, Universidad aRCIS, Revista Encuentro XXI y Editorial Grijalbo Mondadori, y patrocinado, entre otras instituciones, por la CEPAL.
La superioridad inicial de los conquistadores fue marítima y militar, aunque esta última era aún limitada. La única región de tamaño significativo conquistada en ultramar por los europeos fue América, donde, por razones que no nos interesan aquí, los imperios locales no fueron capaces de resistir. En Asia y en Africa, hasta el siglo XVIII los europeos sólo pudieron establecer control sobre algunos puertos, y eso sólo en regiones donde no confrontaron Estados de algún tamaño y eficacia, como China y Japón. En resumen, en los primeros dos siglos y medio, la expansión europea tuvo éxito en gran medida porque las condiciones locales no la inhibieron. La relativa debilidad de los imperios europeos se demostró por su incapacidad para controlar los movimientos de independencia que se desarrollaron en América - tanto en Norteamérica como en América Latina los estados europeos no pudieron resistir por mucho tiempo. ${ }^{1}$

Sin embargo, la clara superioridad técnica, económica y por lo tanto militar del centro sobre la perife-

\footnotetext{
${ }^{1}$ Los británicos reconocieron estas limitaciones rápidamente. Ellos no trataron seriamente de reconquistar los Estados Unidos, aunque ganaron una guerra en 1812-1813; y desde muy temprano después de que las colonias españolas ganaron la independencia, los británicos decidieron abstenerse de intervenciones militares directas, aun en el río de la Plata.
} 
ria se incrementó enormemente en el siglo XIX, gracias a los llamados "instrumentos del imperio" — cañoneras, ametralladoras, artillería - y a la construcción de una infraestructura de apoyo mundial para la supremacía marítima. En el siglo XIX esta infraestructura estaba casi completamente en manos de los británicos, quienes eran entonces la potencia económica y mundial.

Consideremos ahora brevemente las implicaciones políticas de esta situación. Primero, los Estados del centro pudieron fácil y rápidamente tener a su alcance el mundo periférico, pero no al contrario. Gran Bretaña pudo practicar la diplomacia de las cañoneras contra China, pero China no pudo hacer lo mismo en contra de Gran Bretaña. En términos modernos, los Estados Unidos pueden tener acceso a Iraq, pero no se da lo contrario. Segundo, en casi todos los conflictos armados entre el Primer y el Tercer Mundo, el primero ganó las batallas, generalmente con pocas dificultades. $^{2}$

Tercero, el resultado fue una inferioridad política de los Estados del Tercer Mundo, grandes o pequeños, en relación con los del Primer Mundo -como lo demuestran las relaciones entre los Estados Unidos y México, y entre Gran Bretaña y China hasta 1949. Hasta la mitad del siglo XX solamente un Estado del Tercer Mundo, que fue exitoso en imitar a Occidente, pudo escapar a esa inferioridad, y por esto fue incorporado al sistema de poder global: Japón.

Cuarto, los Estados del Tercer Mundo, o el Tercer Mundo como un todo, pudieron contrarrestar esta inferioridad permanente sólo con el apoyo de uno de los poderes del sistema mundial. Esta fue la función de la Unión Soviética durante la Guerra Fría. El caso extremo es Cuba, que ha sobrevivido como un régimen comunista a 170 millas de Key West, gracias al apoyo directo de los soviéticos. El final de la Guerra Fría eliminó este contrapeso al poder del mundo desa-

\footnotetext{
2 Esto no condujo necesariamente a que los poderes del Primer Mundo pudieran ganar la guerra, a menos que ésta fuera una guerra contra los gobiernos locales. La resistencia guerrillera en áreas en donde las condiciones la facilitaron — las montañas Atlas en el norte de Africa, Kurdistán, Afganistán - fue siempre difícil y algunas veces imposible de derrotar permanentemente. El más inteligente de los poderes imperiales, Gran Bretaña, desistió de los intentos por ocupar y administrar áreas como la frontera noroccidental de la India, y después de la Primera Guerra Mundial se contentó con controlarla mediante periódicos bombardeos aéreos, como en Kurdistán.
}

rrollado en general, y al de los Estados Unidos en particular.

Por otra parte, ¿qué tanto tuvo el Primer Mundo que usar su superioridad militar y política? ¿No pudo confiar en las abrumadoras ventajas de su mayor riqueza y desarrollo económico, que aumentaron de manera espectacular, sobre todo durante la Guerra Fría? Sí pudo, en el siglo XIX y durante buena parte del XX. Sabemos, después del final, o de la retirada, de los antiguos imperios de los siglos XVI a XVIII que el dominio del Primer Mundo se incrementó, pero los incentivos para transformar áreas del mundo subdesarrollado en colonias disminuyeron durante el siglo XIX, con algunas notables excepciones. ${ }^{3}$ El ejemplo de Gran Bretaña muestra que la explotación meramente económica del Tercer Mundo no requirió ocupación directa, por lo menos en ausencia de otro competidor occidental. Este fue el "imperialismo del comercio libre" sobre el cual se ha escrito mucho. Pero, por supuesto, se mantuvo una red de bases estratégicas o necesarias para que Gran Bretaña continuara controlando las vías marítimas internacionales. A primera vista, la situación presente de los Estados Unidos parece similar. Sin embargo, espero mostrar que hay diferencias fundamentales.

El resurgimiento del colonialismo de finales del siglo XIX, el llamado "nuevo imperialismo", se debió principalmente a la competencia entre Estados occidentales rivales. Sin embargo, es preciso recordar que éste fue un período en el que por razones económicas y técnicas pasó a ser importante, y sigue siéndolo, un conjunto de materias primas y productos que se concentraban en el Tercer Mundo: petróleo, metales no ferrosos, caucho y varios alimentos tropicales. Estos bienes llamaron la atención de los hombres de negocios occidentales y, como algunos de ellos tenían importancia estratégica, también la de los gobiernos. Con todo, como la historia del petróleo enseña, su explota-

\footnotetext{
3 Las principales fueron los Estados Unidos, Francia, los Países Bajos y la India británica. Estados Unidos estuvo, casi por definición, comprometido con la expansión territorial, y por eso el conflicto con su vecino pobre y atrasado del sur (la guerra con México). Las disputas limítrofes con el otro país desarrollado en el norte del continente americano, Gran Bretaña (en Canadá), fueron negociadas a través de medios diplomáticos pacíficos. Francia, por razones de política interna, se comprometió a la conquista de Argelia, en el sur del Mediterráneo, un área también usada para migración europea. Los Países Bajos y Gran Bretaña (o mejor, las compañías de las Indias Occidentales británica y holandesa) al establecer una base territorial en India e Indonesia se encontraron, por razones que no nos interesan aquí, ante el hecho de tener que ampliar esas bases hasta transformarlas en grandes colonias.
} 
ción no requirió necesariamente una ocupación colonial. $^{4}$

Si miramos con perspectiva histórica, podemos ver que la nueva era de colonialismo (de imperios que insistieron en la ocupación y administración directas) resultó ser relativamente corta. El colonialismo directo fue una moda temporal y duró poco. Se puede ubicar en la vida de una sola persona: por ejemplo, de Winston Churchill, quien vivió desde 1874 hasta 1965. A partir de la revolución industrial, el capitalismo ha necesitado la creación de una economía mundial, dominada por los centros de acumulación de capital, pero esto no requiere necesariamente un sistema colonial formal.

Pero aquí un acontecimiento reciente ha introducido un elemento nuevo. En el último cuarto del siglo $\mathrm{XX}$ el centro de gravedad de la economía mundial, ahora cada vez más globalizada, comenzó a desplazarse en cierta medida desde los países capitalistas originales hacia el Tercer Mundo, lo que es notable en la industria manufacturera. Además desde el surgimiento de la economía japonesa y la crisis del petróleo de los años setenta, la acumulación de capital nativa fuera de Europa y América del Norte ha pasado a ser mucho más importante que antes. ${ }^{5}$ Este cambio fue acelerado por la enorme y creciente diferencia de ingresos entre el Primer y el Tercer Mundo, que impulsó la transferencia de producción con uso intensivo de mano de obra desde las regiones de altos salarios hacia la de salarios bajos (fenómeno bien conocido en México). Por la misma razón, se reforzó la desindustrialización de las regiones industriales pioneras del Primer Mundo.

Así, económicamente hablando, la economía internacional no puede considerarse más como dividida simplemente entre un Primer Mundo que concentraría la mayor parte del producto industrial, lo mismo que su comercialización, y un Tercer Mundo que estaría ligado al primero como productor de materias primas, pero con un sector industrial apoyado por su mercado interno, por ejemplo, en la sustitución de importaciones. (No voy a considerar las economías más cerradas del Segundo Mundo socialista, las que han dejado de existir, como la Unión Soviética, o han cambiado sus

\footnotetext{
4 La división del mundo en colonias estuvo confinada a Africa y el Pacífico. Las Américas casi no fueron afectadas, como tampoco el Asia continental que no había sido conquistada previamente, a excepción de lo que se convirtió en la zona de expansión territorial de Japón en el Asia del este.

5 Antes de los años setenta, incluso Japón, considerable potencia militar desde los inicios del siglo XX, no generaba más del 5\% del producto industrial mundial.
}

políticas, como China.). Hoy el Tercer Mundo incluye las economías de mayor crecimiento industrial, y la industria más orientada a la exportación. Ya al final de los años ochenta, más del $37 \%$ de las importaciones de los Estados Unidos venían del Tercer Mundo y casi un $36 \%$ de sus exportaciones iban a este último.

Por esto, la superioridad económica del Primer Mundo no reside más en ser el más industrializado o tener la economía más "avanzada", con una excepción: hasta la fecha, continúa casi monopolizando la investigación y el desarrollo científico y tecnológico. ${ }^{6}$ Salvo en este ámbito, la superioridad del Primer Mundo reside en operar como un conglomerado económicofinanciero, en lugar de hacerlo como una planta productiva. En él se ubican las oficinas centrales de la mayoría de las grandes empresas transnacionales, las que con todas sus dependencias locales y subsidiarias constituyen parte sustancial de la economía mundial. Tiene la habilidad de establecer el marco de la economía mundial y sus instituciones, como el Banco Mundial y el Fondo Monetario Internacional, las cuales controla. Y su inmensa riqueza le concede el manejo de la mayor parte de los flujos de capital para inversión mundial, y de sus flujos.

Pero, al mismo tiempo, esa superioridad hace más dependiente al Primer Mundo de lo que suceda en el tercero. Desde el punto de vista de la economía, hoy es mucho más importante que antes tener cierto control político, particularmente para los Estados Unidos, la potencia hegemónica del capitalismo actual. El desarrollo económico de este país hasta después de la Segunda Guerra Mundial se cimentó en su mercado interno. Proteger su industria de la competencia extranjera fue tradicionalmente mucho más importante para la economía estadounidense que el libre comercio y la promoción de las exportaciones. Aunque algunas ramas específicas de la industria y las finanzas de los Estados Unidos estuvieron profundamente comprometidas en esta u otra parte de la economía tercermundista - la United Fruit, por ejemplo—, la economía estadounidense como un todo no dependía de sus lazos con el Tercer Mundo, a diferencia de Gran Bretaña, la potencia hegemónica en el siglo XIX.

Esto nos lleva al tema específico que se tratará aquí, cual es la posición internacional y las políticas de los Estados Unidos a partir de la Guerra Fría.

\footnotetext{
6 Aún al final de este siglo, el número de asiáticos y latinoamericanos que han ganado el premio Nobel en ciencias es reducido, y varios entre aquellos que lo han obtenido han trabajado o están trabajando en Europa y los Estados Unidos.
} 
Los Estados Unidos ocupan hoy una posición sin precedentes. Es la única potencia mundial. En el siglo XIX Gran Bretaña ocupó una posición similar, como la única potencia con intereses globales. Los demás países, incluidos los Estados Unidos y Japón, tuvieron a lo sumo intereses regionales. Sin embargo, en términos político-militares Gran Bretaña era una de varias potencias, aunque en un aspecto las superó a todas hasta el siglo XX: la armada británica era tan grande como todas las demás juntas, pero sólo hasta que otras potencias, en especial los Estados Unidos y Japón, empezaron a construir un considerable poder naval. La posición actual de los Estados Unidos, en términos relativos y absolutos, es muchísimo más fuerte. No hay una posibilidad previsible de que otra potencia compita con su poderío nuclear y aéreo. Desde el colapso y desintegración de la Unión Soviética, no hay otro Estado o combinación de Estados que siquiera pueda pensar en retarlo en términos militares.

Me parece por esto importante comparar estas dos hegemonías. Yo observo entre ellas tres diferencias mayores, que no están desconectadas. Los Estados Unidos, a diferencia de la Gran Bretaña del siglo XIX (pero como la Francia revolucionaria y la Unión Soviética), es un imperio ideológico. Quizás por esta razón el imperio estadounidense, a diferencia del británico, aspira a transformar el mundo a su propia imagen y semejanza. En la práctica, esta aspiración se sobrepone a la de dominación político-militar mundial. La tentación por el control es política, no sólo económica: porque a pesar de la presente situación mundial en la cual el libre comercio se ajusta a los intereses de los Estados Unidos, la actitud básica del país ha sido la de proteger e impulsar el capitalismo estadounidense por medio de la acción política. A diferencia de Gran Bretaña en el siglo XIX, los Estados Unidos tienen una larga historia de intervención militar en el extranjero.

Los días de la Pax Britannica fueron distintos. Como era un país relativamente pequeño, Gran Bretaña no pudo darse el lujo de la megalomanía. Por ejemplo, su política europea fue la de "equilibrio de poder". No pretendió convertirse en la potencia europea más poderosa, pero sí velar por que los Estados más fuertes siempre estuvieran enfrentados los unos con los otros, mientras el Estado británico permanecía al margen de las disputas. Como pioneros exitosos de la industrialización mundial, los británicos tenían una enorme confianza en su sistema económico. ${ }^{7}$ También

7 Tanto, que unilateralmente adoptaron el libre comercio y lo mantuvieron por casi un siglo, aun cuando ningún otro Estado se estaban convencidos de que su sistema político era superior a cualquier otro, pero no lo promovieron como modelo general. ${ }^{8}$ Allí donde la Gran Bretaña del siglo XIX se convirtió en modelo, fue por ejemplo y no por diseño: como en el caso de la moda para hombres y en casi todos los deportes practicados internacionalmente, los que fueron todos británicos en su origen.

La Pax Britannica fue, por esto, muy diferente de la Pax Americana, excepto en que la armada británica, en sus días de supremacía, asumió la responsabilidad principal en la vigilancia marítima internacional de actividades como la piratería y (luego de que había sido prohibido) el comercio de esclavos. Gran Bretaña reconoció sus limitaciones. Ningún ministro de asuntos exteriores británico, ni siquiera Palmerston, hubiera dicho, respecto a cualquier parte del mundo, lo que el Secretario de Estado Olney dijo acerca del hemisferio occidental en 1895: 'Hoy los Estados Unidos es prácticamente soberano en este continente, y en la medida en que se ocupa de un asunto, su mandato tiene fuerza de ley. ¿Por qué? ....porque sumado a todos los otros aspectos, sus infinitos recursos combinados con su posición aislada lo hacen dominar la situación y prácticamente ser invulnerable frente a cualquiera o a todas las otras potencias.'

La política de los Estados Unidos, por lo tanto, ha sido consistentemente intervencionista, primero dentro del hemisferio occidental, luego globalmente. Gran Bretaña tuvo muchas colonias, pero no Estados satélites, excepto durante lo que se ha dado en llamar "el momento británico en el Medio Oriente", entre 1918 y 1958. Estados Unidos tuvo pocas colonias, pero aspiró a contar con un sistema de Estados satélites. Recordemos que la forma de operación característica del servicio de inteligencia estadounidense, la CIA, combina específicamente labores de inteligencia con acciones políticas encubiertas.

Además, como hemos visto, primero en el hemisferio occidental y luego globalmente, la política de los Estados Unidos ha estado basada en el supuesto de su poderío abrumador, tanto económico como técnicomilitar, en su área de influencia. Un poder que el país

les unió; ésta fue una política beneficiosa para una economía que se basaba en los intercambios con el Tercer Mundo.

8 Los franceses y los estadounidenses nunca serían como ellos, lo cual fue duro de aceptar, pero inevitable. Los rusos estarían mejor con leyes estables y libertades civiles, pero aún así permanecerían demasiado no británicos. En relación con el Tercer Mundo, los británicos estaban convencidos, principalmente sobre la base de su experiencia como gobernantes de la India, de que la mayoría de sus habitantes estaban incapacitados permanentemente para la libertad. 
siempre ha estado dispuesto a usar si es necesario, y que requiere de los otros Estados algún grado de aceptación y consideración públicas. Los poderes antiguos, acostumbrados a las convenciones y maneras de la diplomacia, normalmente no habían hecho tales exigencias. El supuesto, claramente implícito en la Ley Helms-Burton, es que los Estados Unidos son tan indispensables para el resto del mundo, que su poder nacional puede ser usado para obligar a otros Estados a que se ajusten a las políticas estadounidenses, aun dentro de la jurisdicción de sus propios territorios.

En la Guerra Fría todo esto fue justificado por el peligro soviético, y aceptado por los aliados y satélites de los Estados Unidos como un precio necesario para mantener contento a Washington. ${ }^{9}$ Pero, ¿cuál es la situación hoy? La lista de intervenciones después de la Guerra Fría, cuando ya no existe amenaza soviética alguna, es sorprendentemente larga. Incluye Panamá en 1989, la guerra del Golfo en 1991, Haití en 1994 y varias operaciones con objetivos humanitarios o de pacificación, pero con participación directa de fuerzas estadounidenses, desde Liberia y Somalia, hasta el Kurdistán iraquí y Bosnia. Las más recientes son los bombardeos en Sudán y Afganistán.

De hecho, es obvia 'una continua certeza acerca de una intervención militar como la respuesta definitiva de los Estados Unidos' (Down, 1997, p. 202), para citar un autor estadounidense. ¿Por qué? Porque otros medios de afirmar la influencia estadounidense han pasado a ser menos eficaces, y porque ha aumentado la necesidad real de una constante afirmación de su supremacía. La ayuda económica de los Estados Unidos ha declinado drásticamente, en particular desde que se aprobó la ley Graham-Rudman-Hollings a mediados de los años ochenta, y con ella se debilitó un medio tradicional de influir en otros Estados. El éxito de las sanciones económicas, a las cuales los Estados Unidos han sido adictos, ha disminuido desde el inicio de los años setenta, posiblemente porque la economía estadounidense ha perdido importancia relativa, o porque esas sanciones no son adecuadas para lograr objetivos específicos como el respeto a los derechos humanos o el control del tráfico de drogas. Acciones paramilitares

\footnotetext{
9 Reconocida oficialmente, aunque en forma indirecta, la intervención en los asuntos internos de otros Estados se convirtió en normal - están los casos de Centroamérica, Africa desde los años sesenta, el occidente de Asia- en transgresión del principio legal de no intervención, el cual ha sido codificado desde la Primera Guerra Mundial. Sin duda, esto explica por qué los Estados Unidos justifican la mayoría de sus intervenciones, aun en el caso poco convincente de Granada, en términos de "defensa propia".
}

y encubiertas han tenido resultados inciertos, aunque sin duda han sido altamente eficaces para acosar a gobiernos que los Estados Unidos han desaprobado y perturbar sus operaciones (Angola es un ejemplo triste de casos de esta índole). Por lo demás, tales acciones también son hoy menos eficaces para derrocar gobiernos hostiles, a diferencia de lo que sucedió en los años cincuenta. En todo caso, no son un arma que pueda ser usada unilateralmente, pues necesitan de otro país aliado en la región (Schraeder, 1992, p. 149).

Por otro lado, la globalización de la economía hizo que las actividades de las empresas transnacionales - de cualquier país - fueran más dependientes de la buena voluntad de las autoridades del país en el que operan. La Ley Helms-Burton pretende excluir del territorio estadounidense a todos los extranjeros cuya actividad económica en otras partes del mundo no gusta al gobierno de Washington. Pero este principio es aplicable a todos los Estados. ${ }^{10}$ Un país de tradición tan proteccionista como los Estados Unidos ha estado siempre muy consciente de este elemento político en su comercio exterior, que es muy evidente, por ejemplo, en la presión casi constante del gobierno de Washington sobre el Japón para que éste deje entrar más mercancías estadounidenses en su territorio. Por supuesto, los Estados Unidos se abstienen de amenazar abiertamente a los Estados que no consideran adversarios o son despreciables por su debilidad. Pero les parece útil que todos se den cuenta de que ellos disponen de lo que el primer Presidente Roosevelt — Theodore- llamó "el gran garrote".

Por lo tanto, después del fin de los años ochenta, los Estados Unidos han elaborado una doctrina sistemática de lo que se ha denominado "conflicto de baja intensidad", apropiado a la era posterior a la Guerra Fría. Ya no se basa en la preparación de una gran guerra, pero sí supone la intervención directa y, de ser necesario, la intervención armada de los aliados de Washington o de los Estados Unidos mismos. Aún más: el fin de la Guerra Fría, es decir, del peligro de una guerra mundial, ha quitado los frenos a la máquina guerrera. La guerra del Golfo no hubiera sido posible antes. El mismo Presidente Bush proclamó la nueva doctrina: 'Para los Estados Unidos y sus aliados es

\footnotetext{
10 Sin la autorización nacional para el aterrizaje de aeronaves no hay tráfico aéreo internacional. La propuesta fusión entre las compañías American Airways y British Airways depende de una decisión política de Washington y de la Unión Europea acerca del número de vuelos de una y otra de estas líneas que se debe permitir en el aeropuerto de Heathrow.
} 
preciso construir una estrategia común de estabilidad en el mundo en desarrollo'. Y ¿qué son las amenazas a la estabilidad? Son 'las insurgencias, el terrorismo y el narcotráfico'. Lo que significa —en las palabras del señor R. Cheney, Secretario de Defensa- 'confiar más que antes en fuerzas con alta movilidad, preparadas para la acción inmediata, y —en la jerga del Pentágono- «with solid power-projecting capabilities»: es decir, con capacidad de intervención militar maciza a larga distancia. Con este propósito hemos debido presenciar en los últimos años varios ejemplos altamente visibles de la capacidad estadounidense de intervenir de un momento a otro, en cualquier parte del mundo, por distante que el lugar esté de las bases militares en territorio estadounidense. Basta recordar la guerra del Golfo, Somalia, Bosnia y, hace un par de meses, un ejercicio de paracaidistas en una de las ex repúblicas soviéticas del Asia Central.

Llegado a este punto de nuestro análisis, tenemos que preguntarnos: ¿cuáles son las capacidades y cuáles son los límites de esta hegemonía militar global? Haremos algunas consideraciones al respecto.

En primer lugar, hay una desproporción creciente entre el tamaño y los recursos de los Estados Unidos y aquellos del mundo dominado por los Estados Unidos. No quiero decir que Washington corre el riesgo de lo que el profesor Paul Kennedy de Yale llamó «imperial overstretch», es decir, de tener ambiciones imperiales desmedidas para los recursos disponibles. Tras el fin de la Unión Soviética, no existe otra potencia militar competidora. Dado que no hay en este momento peligro de una guerra mayor, probablemente los Estados Unidos pueden mantener hoy su supremacía militar sin hacer un esfuerzo económico especial. Sin embargo, hoy en día la población de los Estados Unidos constituye no más que $5 \%$ de la población mundial, y el país genera un 10 a $20 \%$ de la producción industrial mundial, proporción que tiende a disminuir progresivamente.

Entonces, los estadounidenses no son en verdad más capaces de "controlar" el mundo en el siglo XXI que los ingleses de controlarlo en el siglo XIX. Intentar mantener la estabilidad política del mundo es un objetivo razonable para los Estados Unidos; pero imponerla con fuerza militar o económica está fuera de su alcance. Lo peligroso es que este país, en su situación de predominio actual, carece tanto de tradición diplomática como de la conciencia existencial de sus límites.

En segundo lugar, a pesar de toda su fuerza, actuando aislados, los Estados Unidos sólo pueden ha- cer valer un poder relativamente modesto y limitado. Necesitan de otros países aliados, porque una gran parte de sus bases militares y de su infraestructura mundial se halla en territorios ajenos. Aquí surge una diferencia con la hegemonía inglesa del siglo XIX, porque las bases del sistema oceánico inglés fueron propiedad inglesa - Gibraltar, las Malvinas, Malta, Singapur, Hong Kong - y así, sucesivamente. Los Estados Unidos ni siquiera en 1973, cuando dominaban la Organización del Tratado del Atlántico Norte (OTAN), pudieron disponer libremente de las bases aéreas de sus aliados en tiempo de paz. Además, hoy la política interna de los Estados Unidos impone límites a las intervenciones militares, sobre todo en la mayoría de esos conflictos "de baja intensidad" contemplados por la estrategia mundial del fin de siglo. Porque esos conflictos no pueden ser combates a distancia, sino entre hombres en el terreno. Bosnia y Chechenia son ejemplos pertinentes. Se sabe, sin embargo, que la opinión pública estadounidense siempre desea victorias militares, pero sin bajas propias. Habría que adaptar tanto la estructura de las fuerzas militares de los Estados Unidos como el espíritu público del país; lo que no es imposible, pero todavía no ha sucedido.

En tercer lugar, en grandes territorios del mundo - en Africa, en buena parte de Asia y hasta en la Europa oriental - se observa hoy la efectiva desintegración de Estados y de un sistema de Estados. No está muy claro cuán útil podría ser la nueva doctrina estadounidense ante los conflictos "de baja intensidad" en tales situaciones de inestabilidad. Es verdad que en caso de guerra el Primer Mundo sin duda ganaría cualquier batalla contra el Tercer Mundo. ¿Y después? ¿Quién garantizaría la estabilidad? Y en esas regiones inestables, ¿dónde encontrar los gobiernos simpáticos, dóciles, pero también capaces de mantenerse? Al contemplar lo que sucede en grandes regiones de Africa, algunos observadores desesperanzados se preguntan: ¿No sería mejor recolonizar estos territorios? Ya no se puede. Se ha perdido el secreto de los imperialismos del pasado, es decir, la pasividad de la gran mayoría de los pueblos colonizados frente a los regímenes conquistadores. En todo caso, hoy en día la abundancia mundial de armas y explosivos eficaces y portátiles es tanta que se necesitan ingentes gastos y movilizaciones permanentes de fuerzas para contener grupos más bien pequeños de activistas armados: notable es el caso de Irlanda del Norte, donde en total no hay más que unos quinientos guerrilleros activos. El cálculo de costobeneficio se vuelve altamente desfavorable, lo que los gobiernos tienen muy presente en casi todos los casos 
que no tocan directamente a la integridad de su territorio. Cabe destacar que en Africa los ejércitos no africanos —incluso el francés, después de cuarenta años de intervencionismo - se están retirando del continente.

Entonces, ¿qué significa de hecho la supremacía militar de los Estados Unidos? ¿Hasta qué punto condicionará la conducta de otros países?

Yo creo que el uso más eficaz del "gran garrote" se da en el mantenimiento del cuasi monopolio de los Estados Unidos en armas de alta tecnología. La estrategia político-militar de este país es doble: por un lado, hacer que las fuerzas militares aliadas dependan de la tecnología y de los abastecimientos estadounidenses, sin los cuales no son capaces de funcionar; y por otro, impedir que los adversarios actuales y potenciales puedan producir u obtener en otra parte armas de alta tecnología. En este sentido, cabe suponer que las relaciones de los Estados Unidos con Iraq después de la guerra del Golfo marcan el perfil futuro de su política frente a pequeños y medianos Estados insumisos. Pero también señalan los límites de la estrategia de Washington.

Queda por examinar un problema sumamente grave, tanto para los Estados Unidos como para todo el Primer Mundo. ¿Cómo proteger su superioridad económica contra la migración de los centros productivos de la economía global hacia el Tercer Mundo? Aunque este problema aún no reviste urgencia inmediata para el Primer Mundo, porque China todavía no se ha transformado en una gran potencia económica mundial, la hegemonía político-militar de los Estados Unidos no puede detener este proceso. Pero este país sí dispone de dos armas poderosas: su riqueza y el hecho de que es indispensable para el funcionamiento de la economía mundial. El objetivo de los viejos centros del poder económico, y de los Estados Unidos en particular, no es ni puede ser otro que mantener la economía global bajo su control. El librecambio universal ha sido siempre el programa de las economías globalmente dominadoras, como es hoy la de los Estados Unidos.

Ahora bien. Tenemos que recordar siempre que el ascenso de los nuevos países industrializados y sobre todo los milagros económicos de los "tigres asiáticos" se han basado en el rechazo de la teología neoliberal del mercado libre. A medida que estas nuevas economías industrializadas, relativamente débiles y casi siempre muy endeudadas, se incorporan a la economía globalizada, se vuelven vulnerables a la presión del Fondo Monetario Internacional y otros cen- tros de crédito internacionales. En estos centros el peso político de los Estados Unidos es predominante. En la República de Corea, bajo la presión y con la ayuda de los Estados Unidos, el Fondo quiere imponer el neoliberalismo (incluido el derecho de empresas extranjeras a comprar el control de empresas coreanas), a una economía que logró en treinta años la más rápida transformación jamás conocida de un país agrario, pobre y atrasado en una de las principales economías industrializadas del mundo. Que logró un aumento casi sin par del nivel de vida, y la transformación política de una dictadura militar desarrollista en algo cercano a la democracia. El objetivo es sin duda el de quebrantar modelos económicos contradictorios del neoliberalismo global, y Estados o agrupamientos que impidan esta estructuración global.

¿La fuerza económica de los Estados Unidos basta para mantener este control? La situación no es permanente: a largo plazo el predominio de los Estados Unidos no puede sobrevivir al crecimiento futuro de la economía global, es decir, a la disminución relativa del peso de su economía. Hasta ayer yo hubiera dicho: estamos todavía en el momento librecambista. Además, enfrentamos no sólo el poder político-económico de los Estados Unidos, sino también una ortodoxia ideológica poderosa. La más peligrosa herencia de los años setenta y ochenta ha sido la conversión de la mayoría de los economistas a la teología del neoliberalismo absoluto. ${ }^{11}$ Las consecuencias de programas económicos de esta índole ya han sido funestas en las regiones del antiguo "socialismo real", y han tenido consecuencias por lo menos discutibles para México. Los países en desarrollo, incluidos los de América Latina, viven bajo la doble presión político-económica de Washington e ideológica de un consenso intelectual que carece de realismo tanto histórico como social.

Pero en los últimos meses se han producido cambios significativos hasta en las preferencias de quienes confieren el premio Nobel. Se está acabando el consenso de los economistas, la utopía de un capitalismo sin problemas, del fundamentalismo neoliberal. Se ha descubierto que el futuro del mundo no es necesariamente la universalización del modelo de capitalismo estadounidense.

Y, por lo tanto, está más claro que antes que hay límites a la hegemonía de los Estados Unidos sobre la economía mundial, como hay límites a su hegemonía militar y política.

11 Lo que es evidente en la nominación de los premios Nobel después de 1975. 


\section{Bibliografía}

Down, R. (1997): The impact of the end of the cold war on interamerican relations: The search for paradigm and principle, Journal of Interamerican Studies and World Affairs, vol. 39, $\mathrm{N}^{\circ} 2$,
Beverly Hills, California, University of Miami, Center for Advanced International Studies.

Schraeder, W.P. (1992): Intervention in the 1990s: US Foreign Policy in the Third World, $2^{\mathrm{a}} \mathrm{Ed}$. 